\title{
The Application of Social Judgment Analysis to Library Faculty Tenure Decisions
}

\section{Anne McCartt}

\begin{abstract}
Using the analytical tool of Social Judgment Analysis, the author examines individual tenure policies. In a hierarchical judgment task, State University of New York at Albany librarians rated profiles of hypothetical candidates. Multivariate regression was used to devise weights and functional forms relating tenure criteria to the assigned ratings. Substantial differences were found for the overall tenure decision and for judgments of research/publication records. More similarities were identified for ratings of university service and organizational participation. An illustrative candidate work sheet is presented. The author contends such an approach would increase the consistency and fairness of tenure decisions.
\end{abstract}

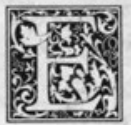

ach faculty member in an academic institution is regularly called upon to evaluate colleagues for the purpose of granting promotion, continuing appointment, or renewal of contract. Not only are individuals asked to make peer review judgments, but a group recommendation is usually made at the departmental level. Although the broad criteria for promotion and tenure are generally consistent across universities and colleges (i.e., research, teaching, and university service), the weights and interpretations applied to these criteria vary across campuses and, to some extent, across departments within a single institution. Within a department, individual faculty members may vary greatly in their respective judgment policies, even if written guidelines exist. Because faculty members may apply their judgment policies inconsistently, two individuals with similar values may still differ in their evaluation of a particular candidate. This inconsistency, together with real disagreement over academic values, results in considerable group conflict, which may be iterated each time a col- league is evaluated. The present climate of cutbacks in higher education exacerbates this conflict, as faculty compete for fewer tenured slots.

Recent court cases have questioned the cloak of confidentiality which has traditionally surrounded the process of tenure and have focused attention on the rights of an individual faculty member within the context of academic freedom. ${ }^{1}$ While one may argue that the tenure process is an inextricable part of academic institutional independence and a flexible tool for applying changing academic standards and goals, one could also question the "fairness" of a process which often involves many vague criteria that may be used in an inconsistent way. A fairer process might involve more clearly defined expectations for tenure, including the ranking or weighting of criteria and more precise measures for fulfillment of the criteria. The process would also ensure more consistent application of the criteria. While judgments of the quality of a person's work are always subjective to some degree, the way in which these judgments are integrated into an overall qvaluation

Anne McCartt is a research associate with the Institute for Traffic Safety Management and Research, State University of New York at Albany. 
need not be subjective or inconsistent.

More precise, consistent policies and procedures would allow the peer review group to focus on the specific qualifications of each candidate. More specific guidelines would also assist nontenured faculty members in understanding academic expectations. Junior faculty members who are not meeting standards might then be more effectively identified prior to a tenure decision.

\section{ACADEMIC STATUS FOR LIBRARIANS}

Over the past few decades it has become increasingly common for universities and colleges to grant faculty status to academic librarians. ${ }^{2}$ The precise definition of "faculty status" varies by institution, but the implementation of "full faculty status" usually means that librarians are expected, officially at least, to fulfill the same criteria for promotion and tenure as teaching faculty. Full faculty status also implies that tenure, promotion, and term renewal judgments involve some degree of peer review. ${ }^{3}$

Peer evaluation may be a drastic change from the way in which personnel decisions in libraries were previously made; academic libraries have been more similar to traditional hierarchical, bureaucratic organizations than have other academic departments. Thus, the collegial judgmental role may be an unfamiliar and uncomfortable one for librarians. ${ }^{4}$ Especially in the areas of teaching and research, librarians have also had difficulty fitting their functions into the professorial role model. In many academic libraries today, the specific criteria and procedures for the application of the criteria are still evolving.

Because faculty status is a relatively recent phenomenon (and still a controversial one) and because librarians must fulfill criteria originally established for professors, one would speculate that the promotion and tenure decisions in an academic library are characterized by more interpersonal conflict than in other academic departments. In traditional academic departments, the application of criteria to a particular candidate may produce heated debate, but the overall judgment policy has a much longer history and has achieved a degree of stability over time. Compared to traditional academic faculties, members of library faculties have had less opportunity to approach consensus on general criteria for promotion and tenure and on measures for these criteria, and these criteria are less likely to be clearly understood and accepted by faculty members. The basis for group conflict often may not be the qualifications of a particular candidate and the degree to which a candidate meets faculty standards, but rather, a lack of consensus on which standards have been, and should be, applied.

This paper examines tenure policies exercised by individual librarians at the State University of New York at Albany (SUNYA). Descriptions of three librarians' individual tenure policies are derived, using the analytical tool of Social Judgment Analysis. Differences between policies are examined, and a model presented which could be used to facilitate deliberations for a tenure candidate. While this paper reports on judgments within a specific environmental context, the methodology is applicable to other academic environments.

\section{SOCIAL JUDGMENT ANALYSIS}

Judgment can be defined as an inferential cognitive process whereby a person uses available information to draw conclusions about unknown qualities or quantities. ${ }^{6}$ The process by which pieces of information are integrated into a single judgment is often referred to as an individual's judgment policy. Two basic approaches are taken to discover a person's judgment policy. The first is to elicit a description of the policy directly from the person. While this is the most commonly used method, an accurate description cannot be obtained until an individual is fully aware of what are typically, very complex intuitive processes. A large body of research has shown that such subjective accounts often produce inaccurate representations of the actual internal judgment process. $^{\text {? }}$

The second method, embodied in Social 
Judgment Analysis, is to infer the policy through an empirical analysis of actual judgments. Social Judgment Theory follows from Tolman and Brunswick's approach to cognition. ${ }^{8}$ Social Judgment theorists posit that the limitations of human cognition are best reduced through the externalization of the internal judgment process. According to Social Judgment Theory, the integration of information forming judgment includes (a) placing a "weight," or measure of relative importance, on each piece of information; (b) developing a specific relation between each piece of information and the overall judgment-referred to as "function form"; and (c) using a particular method for integrating the dimensions of the problem-called the "organizing principle." found that individual differences in these aspects of information usage, and inconsistencies in the application of judgment policies, lead to disagreement in judgments and interpersonal conflict. ${ }^{10}$

Quantitative procedures have been developed to provide externalizations of judgment policies. Based on repeated judgments under a variety of wellspecified conditions, an individual's judgment policy can be captured mathematically through the use of multiple regression procedures. The criterion variable is the individual's judgment, and the predictor variables are the dimensions of the situation judged. The regression equation provides the organizing principle, as well as the weight and function form for each dimension of the problem. ${ }^{11}$

Social Judgment Analysis provides a means to empirically derive descriptions of judgment policies, thereby revealing interpersonal similarities and differences. Clarification of judgment policies not only provides insight for an individual, but it also facilitates the resolution of conflict by allowing individuals to focus on the real differences and similarities of their judgment policies. The technique can also be used to predict a person's future judgments. Finally, Social Judgment Analysis can be used as the basis for developing a model for structuring future decisions.

\section{BACKGROUND ON SUNYA LIBRARY CRITERIA FOR TENURE}

State University of New York at Albany (SUNYA) librarians have had full faculty status for more than a decade. The four academic ranks are as follows: assistant librarian, senior assistant librarian (established in 1977), associate librarian, and librarian. Librarians are typically given initial appointment at one of the two lower ranks. Because persons must be given one "grace year," the tenure process usually begins during a person's fifth year. ${ }^{12}$

The SUNYA Library academic faculty has extensively revised its criteria and procedures several times, most recently in 1978. The current document is designed to abide with campus and statewide SUNY policies, but reflects the special role of librarians within the institution. Thus, the introduction to "Evaluation of Library Academic Faculty for Promotion and Continuing Appointment" states:

The Policies of the Board of Trustees of the State University of New York define librarians as academic faculty, and thereby recognize that librarians make a fundamental intellectual contribution to the educational, research, and public service missions of the university. The Policies also provide that librarians are a separate and distinct Academic Faculty group. This provision recognizes that the intellectual contributions of the Library Academic Faculty of the University differ in kind and emphasis from those of the teaching faculty.

Thus, although the criteria by which librarians are judged must relate to the general criteria applied to all Academic Faculty, they must also relate to the unique role of librarians in the academic community.

The introduction to the specification of criteria states that "the basic quality which must be evident for promotion in academic rank and/or continuing appointment is the ability to perform at a high professional level in areas which contribute to the mission of the institution." Three broad criteria, "intended to serve as general guidelines," are given, along with some explanatory comments. These three criteria are as follows:

1. Effectiveness as a librarian (job perfor- 
mance and continuing growth and development)

2. Contributions to the advancement of the profession (participation in professional/ scholarly organizations, research and publication, consultancies, presentations)

3. University service (involvement in library or university committees and "appropriate" community organizations)

The "Guidelines for Application of Criteria for Continuing Appointment" state that "Effectiveness as a librarian" must have been fulfilled "in an outstanding manner." Additionally, the candidate must also demonstrate "professional activities of high quality" in fulfilling the remaining criteria and "show evidence that such contributions will continue." In summary, the library guidelines are very general and allow a great deal of individual discretion in applying the criteria to tenure candidates.

The internal library procedures for promotion and tenure decisions involve a meeting of the library academic faculty, where each candidate is discussed and a secret vote taken. The results of that meeting and the recommendation of the library director are then forwarded to the campus-wide University Council on Promotion and Tenure.

\section{PARTICIPANTS}

Three librarians were asked to participate in the study. While no attempt was made to use a true sample of the entire professional staff, the participants represented a variety of backgrounds and diverse work experiences. Participants included a nontenured senior assistant, a tenured senior assistant, and a tenured associate. Of the four library departments, only the technical services department was not represented. All three persons had participated in a large number of tenure and promotion decisions.

\section{TASK}

The participants were given profiles of hypothetical tenure candidates and asked to rate each candidate. The pool of actual candidates over the past few years was not large enough to permit use of real cases, but great care was taken to use profiles which were realistic representations of typical candidates considered for tenure.

Based on discussions with the participants, five important and discriminating candidate characteristics were chosen. Although these characteristics may not be all-inclusive, it was felt that these five criteria are the most salient considerations upon which tenure judgments are based, and usually provide sufficient information to make a decision. The five criteria are as follows:

1. Job performance

2. Educational credentials

3. Participation in professional or scholarly organizations

4. Research and publication record

5. University service

An additional criterion, library position, was considered, but eliminated because of its "configurality." That is, it was felt that the position of a candidate (e.g., cataloger) completely changes the way in which the other information is utilized. To deal with this issue, the profiles all represented librarians from a single department, reference and collection development services, by far the largest department.

Once the major factors affecting tenure judgments were identified, cases were constructed which were representative of the environment. When Social Judgment Analysis is used, it is first necessary to establish the precise range of values for each criterion. Second, the values on the criteria must systematically vary in such a way that the interrelationships between criteria and the distribution of criterion values are realistic. When based on participant input, these two steps help ensure that the criteria are well defined, representative, and are uniformly interpreted by all the judges and by the decision analyst.

Quality of job performance and educational credentials were easily defined and understood by the participants. The other three criteria, however, were more complex variables and definition of these became judgment subtasks. For example, the meaning of a "superior" research and publication record is not immediately obvious; evaluation of a candidate's research and publication record is itself a complex judgment, where various types of publica- 
tions and other related activities are weighted differently, and trade-offs are made between the quantity and quality of different types of achievements. Therefore, a hierarchical judgment task was constructed (see figure 1). Subtasks were administered to clarify the precise meaning of a high or low value for the other three criteria.

As seen in figure 1, a rating for participation in professional organizations was based on the extent of an individual's involvement in organizations at the local, state, and national levels, while a university service record has two underlying dimensions: the level of service within the library, and level of service within the wider university community. Both tasks consisted of 25 hypothetical candidate profiles. The subtask for research and publication consisted of six variables, as follows: number of presentations at professional meetings, number of library "inhouse" publications, number of book reviews, quality of journal or newsletter edited, number of articles in refereed journals, and number of articles in nonrefereed journals. Participants were asked to judge 36 research/publication profiles. For the overall tenure judgment, 37 candidate profiles were presented.

For each judgment task the judges were asked to assign a number between 1 and 20 to each candidate profile, where 20 rep-

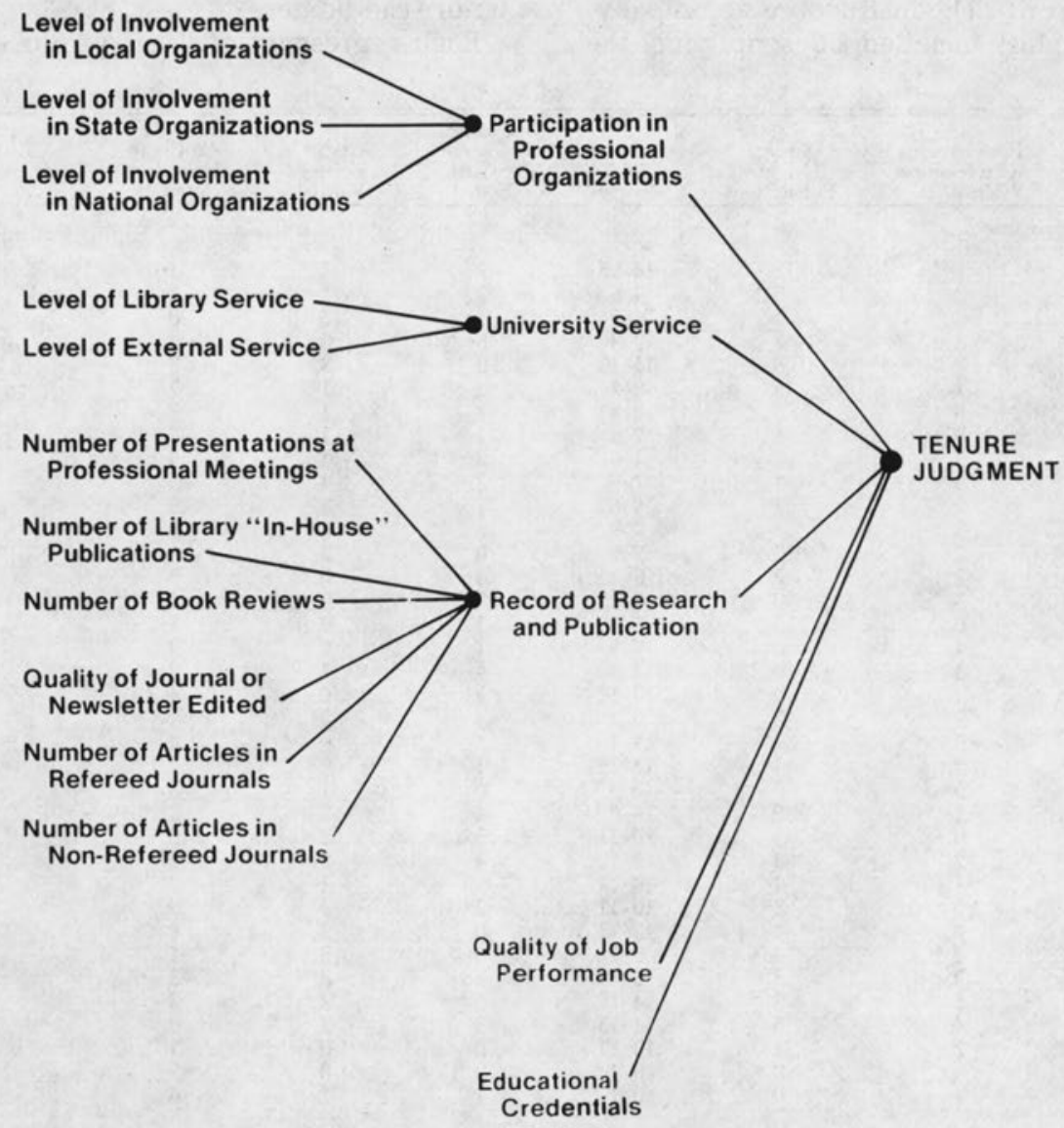

FIGURE 1

Hierarchical Tenure Judgment Task 
resented a superior rating. In all four tasks, the cases were created in such a way that the criteria were totally uncorrelated. Then unrealistic candidate profiles were eliminated, introducing a small degree of intercorrelation between criteria. The intercorrelations, however, remained quite low, ranging from .00 to -.24 for the three subtasks and from .00 to -.18 for the overall tenure task.

All four tasks were presented in the same format and administered at the same time. An example of a judgment task is shown in figure 2. For this task the participant was given a series of hypothetical research and publication profiles and asked to rate each profile with a number between 1 (very poor record) and 20 (superior record). The instructions accompanying the task included a description of the criterion ranges. Participants were asked to assume that the evidence in each case clearly supported the record presented.

\section{RESULTS}

Descriptions of judgment policies for each individual were derived using a nonlinear, additive multiple regression model. Quadratic and linear forms of each criterion were included as the independent variables. For each task the regression analysis identified the weight and function form relating each candidate characteristic to the appropriate rating assigned. Once the individual policies were delineated, it was then possible to compare the policies of the participants and to develop a system for evaluating future tenure candidates.

Each regression analysis produced a

\begin{tabular}{|c|c|c|c|c|c|}
\hline $\begin{array}{l}\text { Presentations } \\
\text { at Professional } \\
\text { Meetings }\end{array}$ & $\begin{array}{c}\text { Library } \\
\text { "In-house" } \\
\text { Publications }\end{array}$ & $\begin{array}{c}\text { Book } \\
\text { Reviews }\end{array}$ & $\begin{array}{c}\text { Quality } \\
\text { of Journal/ } \\
\text { Newsletter } \\
\text { Edited }\end{array}$ & $\begin{array}{l}\text { Articles in } \\
\text { Refereed } \\
\text { Journals }\end{array}$ & $\begin{array}{l}\text { Articles in } \\
\text { Nonrefereed } \\
\text { Journals }\end{array}$ \\
\hline
\end{tabular}

\section{Cases}


TABLE 1

MULTIPLE CORRELATION COEFFICIENTS

\begin{tabular}{lcccc}
\hline \hline & $\begin{array}{c}\text { Organizational } \\
\text { Participation }\end{array}$ & $\begin{array}{c}\text { University } \\
\text { Service }\end{array}$ & $\begin{array}{c}\text { Research/ } \\
\text { Publication }\end{array}$ & Tenure \\
\hline Judge 1 & .87 & .93 & .69 & .95 \\
Judge 2 & .90 & .95 & .87 & .96 \\
Judge 3 & .93 & .97 & .94 & .96 \\
\hline
\end{tabular}

TABLE 2

MEAN JUDGMENTS

\begin{tabular}{lcccr}
\hline \hline & $\begin{array}{c}\text { Organizational } \\
\text { Participation }\end{array}$ & $\begin{array}{c}\text { University } \\
\text { Service }\end{array}$ & $\begin{array}{c}\text { Research/ } \\
\text { Publication }\end{array}$ & Tenure \\
\hline Judge 1 & 12.7 & 10.4 & 13.5 & 9.6 \\
Judge 2 & 10.7 & 9.8 & 12.5 & 9.6 \\
Judge 3 & 11.7 & 10.0 & 12.8 & 10.9 \\
\hline
\end{tabular}

multiple correlation coefficient, $R$, an index of the fit of the judgment regression model to the person's actual judgments. A high multiple $R^{13}$ means that the model provides a good representation of the internal judgment policy, that the model can be used to predict future judgments accurately, and that the judge is applying the policy consistently. However, a low multiple $R$ could be due either to inconsistency on the part of the judge, or to the model's failure to capture the judge's policy. The multiple correlation coefficients are shown in table 1 and are generally quite high, with only three less than .90 and only one less than .85 . This means that the judgment policy descriptions derived are excellent representations of the actual judgment policies exercised by the three participants.

\section{DESCRIPTION AND COMPARISON OF POLICIES}

One way in which individuals may vary is the number of candidate profiles identified as "tenurable." In a general sense, some judges set a higher standard for tenure than others. Mean judgments for each judge were computed and are shown in table 2 . With the exception of the overall tenure judgment, judge 1 had the highest mean judgment and judge 2 the lowest. Judge 1 rated the candidate profiles most favorably in completing the three judgment subtasks. The differences between judges, however, were relatively small. On the tenure judgment task, judge 3 had the highest mean rating, with judges 1 and 2 having the same mean judgment.
Interestingly, the mean judgment for tenure for all three judges fell close to 10 , the arbitrary cutoff point for a negative tenure decision.

Individuals may also differ in the relative importance given a particular criterion. Relative criterion weights for the three subtasks are listed in table 3. Each weight represents the relative contribution of the criterion to the overall judgment and captures the contributions of both the linear and quadratic forms of the criterion.

All three judges had similar weighting schemes for the university service subtask. Service external to the library was always weighted more heavily than internal library service, although the weights assigned to external service range from .56 (judge 1) to .69 (judge 3 ).

For the organizational participation subtask, judges 1 and 2 distributed the weights fairly evenly across the three criteria-level of involvement in local, state, or national organizations. Judge 3, however, assigned no importance to the level of local organizational participation and gave a weight of .63 to activities in national organizations.

Not unexpectedly, the judges differed dramatically in their weighting schemes for the research and publication subtask. None of the judges used all six criteria in rating the research and publication profiles, and judge 1 and judge 2 based their judgments on completely different criteria. Judge 1 used three criteria, as follows: number of library publications, number of book reviews, and the quality of journal or 
TABLE 3

RELATIVE CRITERION WEIGHTS

\begin{tabular}{lccc}
\hline \hline Criteria & Judge 1 & Judge 2 & Judge 3 \\
\hline Task 1: University Service & & & .31 \\
Library service & .44 & .36 & .69 \\
University service & .56 & .64 & \\
Task 2: Organizational Participation & .28 & .32 & .0 \\
Local organizations & .36 & .26 & .37 \\
State organizations & .36 & .42 & .63 \\
National organizations & & & \\
Task 3: Research and Publication & 0 & .70 & 0 \\
Number of presentations & .28 & 0 & 0 \\
Number of library "in-house" publications & .24 & 0 & .08 \\
Number of book reviews & .48 & 0 & .23 \\
Quality of journal or newsletter edited & 0 & .30 & .45 \\
Number of refereed journal articles & 0 & 0 & .24 \\
Number of nonrefereed journal articles & & & \\
Task 4: Overall Tenure Judgment & 1.0 & .60 & .34 \\
Quality of job performance & 0 & .12 & 0 \\
Educational credentials & 0 & .09 & .08 \\
Participation in professional organizations & 0 & .10 & .53 \\
Record of research and publication & 0 & .10 & .06 \\
Unversity service & &
\end{tabular}

newsletter edited. An editorship was given a weight of .48 , nearly equal to library publications $(.28)$ and book reviews (.24) combined. Judge 2 used only two criteria: a weight of .70 was given to the number of presentations at professional meetings, and a much lower weight of .30 was given to the number of articles in refereed journals. Judge 3, using four criteria, found the number of articles in refereed journals (.45) most important. The number of articles in nonrefereed journals and an editorship of a newsletter or journal were weighted almost equally at .24 and .23 respectively. A relatively low weight of .08 was given to the number of book reviews.

The three judges also used markedly different weighting schemes in evaluating candidates' overall qualifications for tenure. Judge 1 looked at job performance as the sole criterion when evaluating profiles for tenure. Judge 2 used all five criteria but also placed the greatest importance on job performance $(.60)$. The remaining four criteria all received similar weights, ranging from .09 to .12 . Judge 3 used all criteria except educational credentials. Most heavily weighted was the research/publication criterion (.53). Job performance was given a weight of .34, with university service and organizational participation considered much less important with weights of .06 and .08 , respectively.

A weighting scheme alone does not completely describe an individual's judgment policy. Another component is the functional form relating each criterion to the judgment. For the subtasks in organizational participation, university service, and for the tenure task, the functional forms for the three judges were all increasing functions, although not all were linear. The function form for the research and publication record subtask are presented in figure 3 , along with the relative weights. With the exception of library publications, the function forms increase. That is, the higher the level on the cue, the higher the given rating. The function for number of library publications, used only by judge 1 , decreases up to three publications, and then increases. Taken together, the function forms and weights for each judge describe the judgment policy for evaluation of research and publication records. As figure 3 shows, the three judges had fundamental disagreements over how a particular record of research and publication should be evaluated. For ex- 


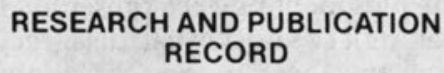

Number of presentations at Professional Meetings

Number of Library
"In-House" Publications

Number of Book Reviews

Quality of Journal or Newsletter Edited

\section{Number of Articles in Refereed Journals}

Number of Articles in Non-refereed Journals
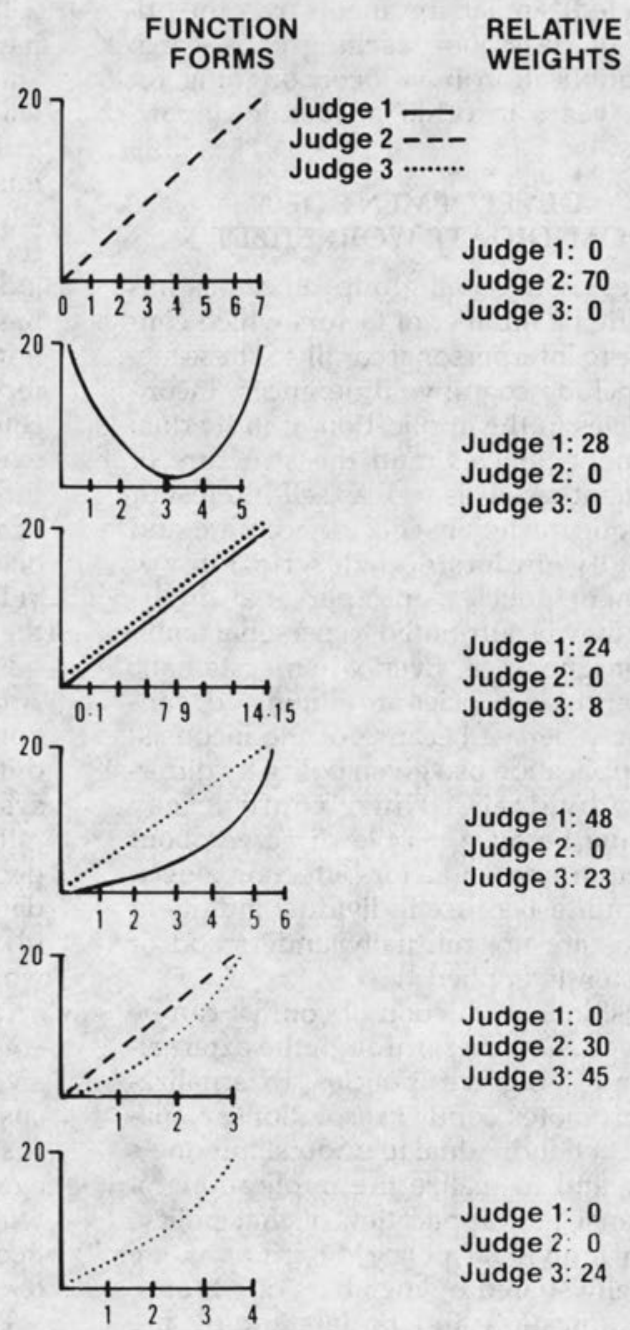

Judge 1: 28 Judge 2: 0 Judge 3: 0

Judge 1: 24 Judge 2: 0 Judge 3: 8

Judge 1: 48 Judge 2: 0 Judge $3: 23$

Judge 1: 0 Judge 2: 30 Judge $3: 45$

Judge 1: 0 Judge 2: 0 Judge 3: 24

\section{FIGURE 3}

Judgment Policies for Research and Publication Subtask

ample, a candidate whose activities had been published in refereed journals, or presented at professional meetings, would receive a high rating from judge 2 , a 0 rating from judge 1 , and a mediocre rating from judge 3.

In summary, Social Judgment Analysis revealed substantial differences among the three participants in their evaluations of hypothetical research and publication records and of hypothetical profiles of ten- ure candidates. The analysis revealed more similarities in judgment policies for university service and organizational participation. Disagreement over what constitutes a "superior" research/publication record is not surprising; as with faculty status, an increasing emphasis on research and publication in academic libraries is a relatively recent phenomenon. Conflict over the relative importance of research and job performance could also be 
predicted; similar arguments over the primacy of classroom teaching or research and publication have been ongoing for many years in other academic departments. ${ }^{14}$

\section{DEVELOPMENT OF A CANDIDATE WORKSHEET}

Research in small group processes has identified a number of factors which contribute to interpersonal conflict. These factors include cognitive differences, inconsistencies in the application of individual judgment policies, and the structure of judgment tasks, as well as self-interest or emotion. In the absence of accurate and mutually understood descriptions of judgment policies, interpersonal differences may be attributed to personal ambition or ignorance. Even when systematic differences in policies are eliminated, conflict may persist because of the inconsistent application of a given policy by different individuals. Thus, conflict may continue because people disagree about the importance of factors affecting a decision and/or because individual judgment policies are not mutually understood or consistently applied. ${ }^{15}$

Substantial reduction of conflict can be achieved, however, through the externalization of judgment policies. Externalization promotes conflict resolution by enabling each individual to understand one's policy and to realize the implications of the consistent application of that policy. When individual policy descriptions are mutually shared by members of a group, communication and understanding are enhanced; differences and similarities and potential areas of compromise can be identified. Furthermore, the comparison of policies can be accomplished within a common perceptual framework and through a common vocabulary. Discussion turns from the particular case to the characteristics of the task itself. ${ }^{16}$ Externalization of judgment policies, or " cognitive feedback," through Social Judgment Analysis has been demonstrated to be helpful in a variety of group problemsolving situations; conflict has been substantially reduced or eliminated. ${ }^{17}$
The judgment policies presented in this paper reflect substantial disagreements among the three judges concerning the way in which tenure criteria should be used to evaluate candidates. Although the multiple correlation coefficients are generally high, there also appears to be some inconsistency present in the most complex judgment task, research and publication. Based on the research reported above, however, this initial disagreement, likely representative of the faculty as a whole, could be reduced significantly through the externalization of judgment policies through Social Judgment Analysis. When descriptions of individual policies, based on mutually understood criteria, are provided, faculty consensus could emerge on the weights and function forms.

Finally, the results of Social Judgment Analysis can serve as the basis for developing a system for evaluating tenure candidates. It is not suggested that a rating system replace faculty deliberations, but rather that the system serve as the point of departure for faculty discussion of a candidate. The system would reflect library faculty consensus on the appropriate weights and function forms for the tenure criteria. It would be understood, of course, that the criteria could not be inclusive of all possible relevant activities. Discussion for each tenure case could focus first on how well the candidate performed against the group judgment model and would then turn to additional relevant aspects of the candidate's record or any extenuating circumstances.

To demonstrate the way such a system works, the policies of judge 3 were used to develop an illustrative candidate worksheet. In figure 4 , the performance of a hypothetical tenure candidate is given for each criterion. For example, this candidate's research and publication record includes five presentations at professional meetings, one library "in-house" publication, four to six book reviews, editing a newsletter for a local organization, and four journal articles (two published in refereed journals). Summary of a candidate's qualifications could be completed by the committee responsible for collecting the 


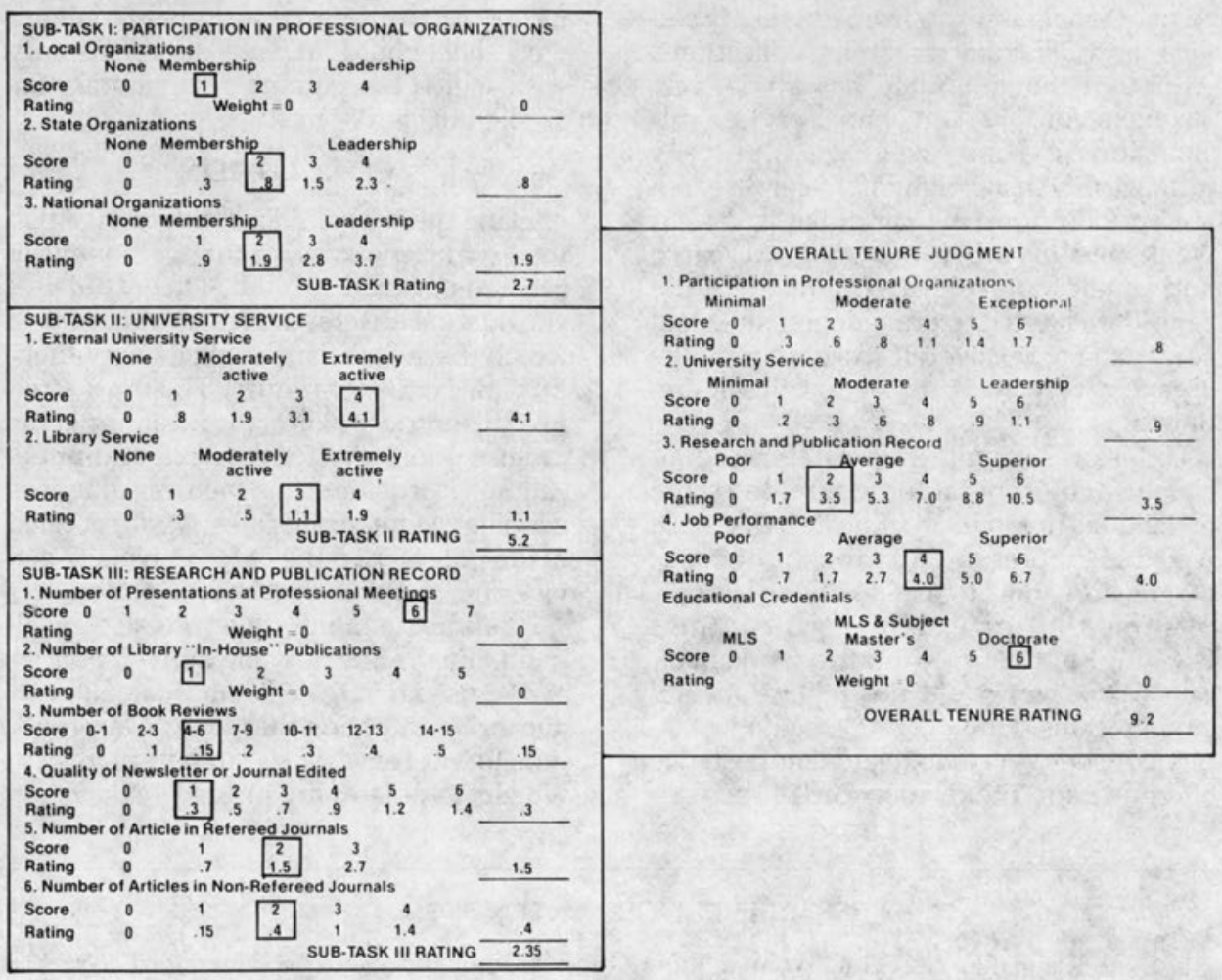

FIGURE 4

Illustrative Rating Sheet Based on Judge 3's Judgment Policies

evidence for each tenure case, with the scores based on the information included in the candidate's vita. A subtask for job performance might also be desirable, to derive more precise measures for the quality of work performed by a candidate.

Using weights and function forms derived from Social Judgment Analysis, the performance scores for the three subtasks can be converted into ratings. To facilitate the conversion of performance scores into weighted evaluative ratings, the worksheet shows the corresponding weighted judgment rating directly under each performance score. For example, the ratings for research and publication in figure 4 incorporate the functions and weights for judge 3 listed in figure 3 . An overall evaluation of 2.35 (from a possible 6 points) for research and publication is obtained by summing the weighted ratings of 0 for presentations, 0 for library publications, .15 for book reviews, .3 for editorship, 1.5 for refereed journal articles, and .4 for nonrefereed journal articles. Similar calculations result in performance ratings of 2.7 for organizational participation and 5.2 for university service.

The subtask evaluations, together with scores for job performance and educational credentials, serve as the basis for an overall tenure judgment. The relative weights and function forms for the five criteria once again provide a precise relationship between the scores and the tenure judgment. In the hypothetical case shown in figure 4, the candidate receives an overall tenure rating of 9.2 out of 20 possible points. Of the 9.2 points, 4.0 are derived from job performance, .8 from organiza- 
tional participation, .9 from university service, and 3.5 from research/publications. Although the candidate has a relatively strong record in university service, this criterion was not weighted highly by judge 3 . Given a weight of .53 for research and publication, the candidate's case is weakened by a below-average research and publication record. The fact that the candidate has a doctorate degree does not contribute to the overall score, since judge 3 gave a zero weight to educational credentials.

Unless the faculty had established an absolute cutoff point for tenure, the score of 9.2 does not in itself indicate a decision. If figure 4 represented a group judgment, discussion might turn to those accomplishments, for example, consulting, teaching, not covered by the worksheet. The worksheet could not replace faculty deliberations. However, if based on a faculty consensus on the relative importance of criteria and the relationship of each cri- terion to the tenure judgment, such a worksheet could increase the consistency with which the policies of the library are applied to candidates.

\section{CONCLUSION}

Using the tool of Social Judgment Analysis, tenure policies for three academic librarians were derived. These policies show wide discrepancies in the way in which these librarians evaluate hypothetical candidates for tenure. The most striking differences were found among the judgment policies for research and publication records, and for the overall tenure profiles. More similarities were revealed in the judgment policies for university service and organizational participation.

A candidate rating sheet was also developed, illustrating how the derived policies can be used to rate each candidate. It is the author's contention that such an approach would increase the consistency with which candidates are judged.

\section{REFERENCES AND NOTES}

1. Dene Kleiman, "Academic Women Show Gains in Combating Sex Discrimination," New York Times, (15 July 1980), p.1; Edward B. Fiske, "Jailing of a Professor Heightens Fears for Campus Independence," New York Times, (14 Sept. 1980), p.1; Edward B. Fiske, "The Courts in Tenure Cases: Must Faculty Disclose Votes," New York Times, (1 Dec. 1981), sec. 3, p.1.

2. Virgil F. Massman, Faculty Status for Librarians (Metuchen, N.J.: Scarecrow, 1972), p.11-21.

3. Ibid, p.14-15; "Statement on Faculty Status of College and University Librarians," College \& Research Libraries News, 35:26 (Feb. 1974); "Standards for Faculty Status for College and University Librarians," College \& Research Libraries News, 35:112-13 (May 1974).

4. Martha J. Bailey, "Some Effects of Faculty Status on Supervision in Academic Libraries," College and Research Libraries 37:49-50 (Jan. 1976); Dennis W. Dickinson, "Some Reflections on Participative Management in Libraries," College and Research Libraries 39:257 (July 1978).

5. Massman, Faculty Status, p.60-63, 200; Beverly J. Toy, ed., "The Role of the Academic Librarian: A Symposium," Journal of Academic Librarianship 4:128-38 (July 1977); Association of College and Research Libraries, Systems and Procedures Exchange Center, The Status of Librarians: An Overview, Spec Kit \#61 (Washington, D.C.: Feb. 1980), p.2.

6. John Rohrbaugh, "Improving the Quality of Group Judgment: Social Judgment Analysis and the Delphi Technique," Organizational Behavior and Human Performance 24:73-92 (Aug. 1979).

7. See for example, Paul J. Hoffman, "The Paramorphic Representation of Clinical Judgment," Psychological Bulletin 57:116-31 (Mar. 1960); Paul Slovic, "Analyzing the Expert Judge: A Descriptive Study of a Stockholder's Decision Processes," Journal of Applied Psychology, 53:255-63 (Aug. 1969); Richard L. Cook and Thomas R. Stewart, "A Comparison of Seven Methods for Obtaining Subjective Descriptions of Judgmental Policy," Organizational Behavior and Human Performance 13:31-45 (Feb. 1975); Walter Morely Balke, Kenneth R. Hammond, and G. Dale Mayer, "An Alternative Approach to Labor-Management Negotiations," Administrative Science Quarterly 18:331-27 (Sept. 1973).

8. Egon Brunswick, "Organismic Achievement and Environmental Probability," Psychological Review 50:255-72 (May 1943); Edward C. Tolman, Purposive Behavior in Animals and Men (New York: Century, 1932); Edward C. Tolman and Egon Brunswick, "The Organism and the Causal Texture of the Environment," Psychological Review 42:43-77 (Jan. 1935). 
9. John Rohrbaugh, "Making Decisions about Staffing Standards: An Analytical Approach to Human Resources Planning in Health Administration," (manuscript submitted for publication), p.7.

10. Kenneth R. Hammond, "New Directions in Research on Conflict Resolution," Journal of Social Issues, 21:44-66 (July 1965); Kenneth R. Hammond and Berndt Brehmer, "Quasi-rationality and Distrust: Implications for International Conflict," in Human Judgment and Social Interaction, Leon Rappoport and D. A. Summers, eds. (New York: Holt, 1973); Kenneth R. Hammond and others, "Social Judgment Theory," in Human Judgment and Decision Processes; Formal and Mathematical Approaches, Martin F. Kaplan and Steven Schwartz, eds. (New York: Academic, 1975).

11. Kenneth R. Hammond "Probabilistic Functioning and the Clinical Method," Psychological Review, 62:255-62 (July 1955); Hoffman, "The Paramorphic Representation."

12. Faculty appointed at the higher ranks are usually considered for tenure in the first year of the term appointment, with tenure available after three years. Such faculty are typically given an initial two-year visiting librarian appointment prior to the term appointment.

13. Generally, multiple $R$ s between .70 and .80 are regarded as indicative of a statistically adequate judgment model. See Kenneth R. Hammond and others, "Social Judgment Theory: Applications in Policy Formation, " in Human Judgment and Decision Processes in Applied Settings, Martin F. Kaplan and Steven Schwartz, eds. (New York: Academic, 1977).

14. Massman, Faculty Status, p.60-63.

15. Berndt Brehmer," 'Social Judgment Theory and the Analysis of Interpersonal Conflict," Psychological Bulletin, 83:985-1001 (Nov. 1976).

16. Derick O. Steinmann and others, "Application of Social Judgment Theory in Policy Formulation: An Example," The Journal of Applied Behavioral Science 13:71-72 (Jan.-Feb.-Mar. 1977).

17. See, for example, Leonard Adelman, Thomas R. Stewart, and Kenneth R. Hammond, "A Case History of the Application of Social Judgment Theory to Policy Formulation," Policy Sciences, 6:137-59 (June 1975); Kenneth R. Hammond and others, Report to the Denver City Council and Mayor Regarding the Choice of Hand gun Ammunition for the Denver Police Department, Program of Research on Human Judgment and Social Interaction Report No. 179 (Boulder: Institute of Behavioral Science, University of Colorado, 1975); John Rohrbaugh, "Improving the Quality of Group Judgment: Social Judgment Analysis and the Nominal Group Technique," Organizational Behavior and Human Performance, 28:272-88 (July 1981); Rohrbaugh, 1979; Rohrbaugh, manuscript. 